\begin{tabular}{|c|c|c|}
\hline 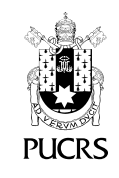 & $\begin{array}{l}\text { ESCOLA DE } \\
\text { HUMANIDADES }\end{array}$ & $\begin{array}{l}\text { Revista Digital do Programa de Pós-Graduação em Letras da PUCRS } \\
\text { Letrônica, Porto Alegre, v. 13, n. 1, p. 1-18, jan.-mar. } 2020 \\
\text { e-ISSN: } 1984-4301\end{array}$ \\
\hline def $\mathrm{http}: / / \mathrm{dx}$ & $\mathrm{rg} / 10.15448 / 1984-4301.2020 .1 .34581$ & \\
\hline
\end{tabular}

\title{
Editora Mulheres, Zahidé Muzart e um caso relevante de edição de livros no Brasil ${ }^{1}$
}

\author{
Zahidé Muzart and her publishing house Mulheres, a relevant case \\ of book publishing in Brazil \\ La editorial Mulheres, la editora Zahidé Muzart, y un caso relevante \\ de edición de libros en Brasil
}

\author{
Ana Elisa Ribeiro ${ }^{2}$ \\ orcid.org/0000-0002-4422-7480 \\ anadigital@gmail.com
}

\section{Sérgio Karam ${ }^{3}$}

orcid.org/0000-0001-9548-7293

sbkaram@uol.com.br.

Recebido em: 21 jun. 2019

Aprovado em: 26 set. 2019

Publicado em: 7 abr. 2020.

\section{(c) (1)}

Artigo está licenciado sob forma de uma licença Creative Commons Atribuicão 4.0 Internacional.
Resumo: Este texto se guia pelos seguintes questionamentos, já que são muitas as variáveis da relação entre mulheres e edição: O que temos investido em fazer? "História feminista da edição ou história da edição feminista? História das editoras mulheres? História das casas editoras feministas?" Em todo caso, faltam investigações mais estruturadas para todas essas perguntas, no Brasil. Nosso projeto mais amplo dedica-se à questão das editoras mulheres, seja lá que tema ou linha editorial elas executem. O caso deste texto, em especial, é o de dar alguma resposta à questão das editoras mulheres brasileiras que optam por publicar uma linha editorial ligada ao feminismo. Neste trabalho, com base em pesquisa documental e bibliográfica, apresentamos uma narrativa sobre a editora Mulheres e uma de suas fundadoras, a professora Zahidé Muzart, além de recompormos o catálogo da casa editorial, tanto quanto possivel, com base nas informações dos próprios livros e em pesquisas em acervos digitais.

Palavras-chaves: Editora. Zahidé Muzart. História Editorial do Brasil. Mulheres na Edição. Livros feministas.

Abstract: Since there are many variables in the relation between women and edition, this text dialogues with the following questions: What have we invested in doing? "A feminist history of edition or a history of feminist edition? A history of women publishers? A history of feminist publishing houses?" Anyway, in Brazil there is a lack of serious investigation about these matters. The broad perspective of our project has to do with women publishers in general, whatever editorial line or theme they come to practice. In this specific text we try somehow to answer a number of questions related to Brazilian women publishers that choose an editorial line connected with feminism. Based in documental and bibliographical research, we present a narrative about the publishing house Mulheres and one of its founding members, professor Zahidé Muzart, and we try as well to recompose its catalogue, as completely as possible, based on data found in the books themselves and in research on digital collections. Keywords: Publishing House. Zahidé Muzart. Brazilian Books History. Women Publishers. Feminist Books.

Resumen: Las siguientes preguntas ayudan a conducir a este trabajo, una vez que sean muchas las variables de la relación entre las mujeres y la edición: Qué tenemos invertido en hacer? "Historia feminista de la edición o historia de la edición feminista? Historia de las editoras? Historia de las editoriales feministas?" De hecho, en Brasil, faltan investigaciones más estruturadas conducidas por estas preguntas. Nuestro proyecto más amplio está dedicado a la cuestión de las editoras mujeres. sea cual for su tema o línea editorial. El caso presentado en este texto, especialmente, es el de alcanzar alguna respuesta a la cuestión de las editoras brasileñas

\footnotetext{
Este trabalho foi primeiramente apresentado de forma oral no simpósio "El espacio iberoamericano del libro. Cartografias de la edición literaria (siglos XX y XXI)", a convite dos coordenadores professores José Luis de Diego e Fábio Espósito, durante o X Congresso Internacional Orbis Tertius, na Universidad de La Plata, Argentina, em maio de 2019. Tendo essa missão cumprida, o texto foi finalizado para publicação, nesta versão ampliada e detalhada, que ora apresentamos.

2 Centro Federal de Educação Tecnológica de Minas Gerais, Programa de Pós-Graduação em Estudos de Linguagens, Belo Horizonte, MG, Brasil.

3 Universidade Federal do Rio Grande do Sul, Programa de Pós-Graduação em Letras, Porto Alegre, RS, Brasil.
} 
que eligen publicar libros en una línea editorial vinculada al feminismo. En este trabajo, basado en investigaciones documentales y bibliográficas, presentamos una narrativa sobre la editorial Mulheres e una de sus fundadoras, la profesora catarinense Zahidé Muzart, además de recomponermos el catálogo de la casa editorial, tanto cuanto posible, con base en las informaciones de los própios libros publicados y en investigaciones en algunas colecciones digitales.

Palabras claves: Editorial. Zahidé Muzart. História Editorial de Brasil. Mujeres en la Edición. Libros feministas.

\section{Considerações iniciais sobre uma narrativa "revista/revisada/revisitada"}

Em 2 de junho de 2017, em um dos auditórios da Faculdade de Letras da Universidade Federal de Minas Gerais, apresentamos pela primeira vez para um público especializado, um resultado preliminar de uma pesquisa que tem o objetivo - um tanto pretensioso, dada a magnitude da tarefa - de mapear e narrar histórias de mulheres editoras no Brasil. Omitidas das narrativas oficiais ou simplesmente desconhecidas por falta de apuração mais dedicada, muitas profissionais do livro parecem não ter existido na história editorial brasileira, em uma primeira e distraida visada4. "IX Colóquio Mulheres em Letras" era o nome do evento da UFMG, sob a liderança da profa. Constância Lima Duarte, experiente pesquisadora das escritoras brasileiras.

Após uma breve apresentação, em que mostramos as lacunas deixadas pela falta de obras que contem a história de mulheres editoras do Brasil, arriscamo-nos em uma lista muito preliminar de nomes de figuras femininas que parecem ter sido relevantes na cena editorial nacional, em periodos diversos do século XX. Parte da plateia, muito atenta, reagiu com uma pergunta em tom exclamativo: "Onde está a Zahidé?" Era uma surpresa tão genuina quanto frustrada. De fato, em apurações tentativas, o nome de Zahidé Muzart, professora e editora da Editora Mulheres, não constava de nossa bibliografia. E isso era algo a ser prontamente corrigido.

Obviamente, os inícios de qualquer pesquisa podem ser compreendidos e até perdoados. $O$ caminho pela frente pode ser difícil e longo, e esse era o caso. A histórica editora gaúcha-catarinense Zahidé Lupinacci Muzart5 ${ }^{5}$, de finais do século XX, seria incluida entre os resultados da pesquisa e não apenas como uma das mulheres que fizeram um trabalho relevante no país, em especial, para os estudos feministas e de gênero, mas como uma das pioneiras da história editorial nacional, com relevância extensiva para a América Latina ${ }^{6}$.

Neste trabalho, com base em pesquisa documental e bibliográfica, apresentamos uma narrativa sobre a editora Mulheres e uma de suas fundadoras, a professora Zahidé Muzart (Cruz Alta, 1939-Florianópolis, 2015), além de recompormos o catálogo da casa editorial, tanto quanto possivel, com base nas informações dos próprios livros e em pesquisas em acervos digitais, como o da Biblioteca Nacional e o hub de "sebos" Estante Virtual, o que dá a ver e evidencia a relevância e o impacto dessa editora para a história editorial brasileira.

\section{1 "Editora e editora, onde começava uma e onde terminava a outra?"}

Este texto, propositadamente mais narrativo que teórico, encontra diálogo e eco nos questionamentos que a pesquisadora argentina Daniela Szpilbarg (2018, p. 1, tradução nossa) se

\footnotetext{
4 Veja-se, por exemplo, a citação ligeira feita a Zahidé Muzart e à Editora Mulheres na colossal obra de Laurence Hallewell (2005), 0 livro no Brasil, que tem funcionado como referência sobre história das editoras desde que foi lançada, nos anos 1980 . Claro está que a primeira edição deste livro data de um periodo em que Muzart era viva e sua produção ocorria fora do eixo Rio-São Paulo, produtor da narrativa hegemônica sobre quase tudo no pais, mas, de outro lado, promotor de muitos apagamentos. Na edição de 2005 (revista e ampliada, com mais de 800 páginas), O livro no Brasil dedica cinco linhas à editora catarinense, exatamente assim, com equívocos nos nomes: "Nova também é a Editora das Mulheres, fundada em Florianópolis em 1996, por Zahidé Muzatti, Elvira Sponholz e Susana Funk professoras universitárias aposentadas, com o objetivo de reeditar obras de autoras femininas do passado brasileiro. Seu primeiro título foi uma edição fac-similar da obra de Ignez Sabino, Mulheres Illustres do Brazil, de 1899. Surpreendentemente, talvez, este Estado é bem provido de pontos-de-vendas de livros". (HALLEWELL, 2005. p. 619-620, grifo nosso)

5 Graduada em Letras Neolatinas pela Pontifícia Universidade Católica do Rio Grande do Sul (1961); em Música pela Escola de Artes da Universidade Federal do Rio Grande do Sul; doutora em Letras pela Faculté des Lettres et Sciences Humaines, Université de Toulouse-Le Mirail (1970), pós-doutora pela Ecole des Hautes Etudes em Sciences Sociales, Paris (1983-1984). Coordenou o Instituto de Estudos de Gênero - IEG/UFSC e foi editora da revista Estudos Feministas (MOREIRA, 2012).

6 Em diversas partes do mundo, o acesso das mulheres a cargos de decisão no campo editorial se dá na segunda metade do século XX Nos anos 1990, no Brasil, é possivel identificar um boom do surgimento de editoras fundadas e dirigidas por mulheres. As razões disso podem ser inferidas (mudanças políticas e comportamentais, incluindo uma absorção de pautas feministas dos anos 1970) e devem ser ainda melhor analisadas e explicadas, algo que não faremos aqui. Para outro caso relevante de casa editorial dirigida por uma mulher, ver Ribeiro (2019).
} 
faz, já que são muitas as variáveis da relação entre mulheres e edição: O que temos investido em fazer, afinal? "História feminista da edição ou história da edição feminista? História das casas editoras mulheres? História das editoras feministas?" Em todo caso, faltam investigações mais estruturadas para todas essas perguntas, ao menos no Brasil.

Nosso projeto mais amplo dedica-se à questão das editoras mulheres, seja lá que tema ou linha editorial elas executem. O caso deste texto, em especial, é o de dar alguma resposta à questão das mulheres editoras brasileiras que optam por publicar uma linha editorial ligada ao feminismo. ${ }^{7}$ No entanto, diferentemente da Argentina, que conta mais facilmente uma história de agentes da edição (não necessariamente feminista) como Victoria Ocampo (1890-1979) e outras tantas mais conhecidas ${ }^{8}$, ao longo do século $X X$, temos grande dificuldade de narrar nossas editoras, mesmo as mais relevantes, no campo da publicação de livros, em especial dos literários.

A Editora Mulheres foi fundada em 1995 pela então professora recém-aposentada da Universidade Federal de Santa Catarina (UFSC) Zahidé Lupinacci Muzart ${ }^{9}$ e outras duas parceiras, também aposentadas: Elvira Sponholz e Susana Bornéo Funck. O objetivo do trio era republicar obras de escritoras brasileiras do século XIX, a partir das pesquisas acadêmicas que traziam à tona o talento e a existência dessas mulheres apagadas pela narrativa hegemônica sobre a história da literatura brasileira ${ }^{10}$. Em outras palavras, objetivava-se produzir uma espécie de rasura em nossa história literária e, por contiguidade, editorial, preenchendo lacunas importantes em nossa narrativa da cultura. Afirma Ramos (2016, p. 182) que a Editora Mulheres intentava "recuperar, editar ou reeditar obras de escritoras do passado, sejam elas brasileiras ou não". Quanto à dedicação de Muzart, Ramos declara: "A homofonia na minha leitura ao falar editora/Editora me remete tanto ao campo editorial quanto à professora e pesquisadora Zahidé Lupinacci Muzart, cujos papéis se fundiram e se confundiram no fazer história literária. Editora e editora, onde começava uma e onde terminava a outra?". Com o passar dos anos, um grande e coeso grupo de pesquisadoras se formou, dando corpo a um empreendimento feminista, editorial e de investigação no Brasil, absolutamente performativo, como descreve Ramos, neste trecho:

Com Zahidé foi possivel ampliar a história cultural brasileira e escrever uma história que não apenas incluiu nomes de autoras e obras, mas apresentou, em uma linha editorialmente coerente, outras e silenciadas formas de ler e de escrever, especialmente porque o trabalho editorial da Editora Mulheres foi cercado de paratextos: olhares criticos contemporâneos de pesquisadoras que se debruçavam sobre os textos e sobre a teoria que deles emergiam. [...] Fizemos, fazemos e faremos parte desse coro de muitas e afinadas vozes da história do feminismo. Seja fazendo gênero ou reescrevendo, no Brasil, mundos de mulheres. Como ela sonhou. Como ela acreditou (RAMOS, 2016, p. 182).

Segundo a autora, Muzart se referia à Mulheres, modestamente, como "uma editora de fundo de quintal", já que não havia funcionários, sede ou distribuidores. A despeito disso, foi possivel escrever "um importante capítulo na história do livro no Brasil", explicitando-se a força que, no século XX, uma pequena editora pode ter, em sua relação com a circulação e a difusão do livro e do conhecimento, e mesmo a importância do fomento à pesquisa eà

\footnotetext{
Foi o caso da brasileira Rose Marie Muraro, da editora Rosa dos Tempos, a quem não nos dedicaremos neste trabalho, mas em outros. 8 Szpilbarg (2018) cita ainda, nominalmente, Ana Maria Cabanellas, Gloria Rodrigué, Kuki Miler, Trini Vergara, Adriana Hidalgo, além de Adriana Astutti e Sandra Contreras (da editora Beatriz Viterbo, de Rosario), para mencionar alguns exemplos que nos remetem aos anos 1970. Ainda assim, admite que a narrativa hegemônica é masculina sobre personagens homens, tais como Arnaldo Orfila Reynal, Antonio Zamora ou Boris Spivacow, entre outros.

9 De acordo com Ramos (2016, p. 181), depois de aposentada, Muzart, pesquisadora 1A do Conselho Nacional de Desenvolvimento Científico e Tecnológico - CNPq por muitos anos, dedicou-se ao Núcleo Literatura e Memória (nuLIME), à linha de pesquisa Crítica Feminista e Estudos de Gênero do Programa de Pós-Graduação em Literatura; à coordenação do Instituto de Estudos de Gênero - IEG; à organização de dez edições do Seminário Internacional Fazendo Gênero; à editoria de artigos e de resenhas da Revista de Estudos Feministas; mas especialmente, à Editora Mulheres, cuja tarefa, nada modesta num campo estruturalmente machista, seria "reescrever uma nova história da literatura brasileira, dando visibilidade às escritas de mulheres do século XIX e à crítica e à teoria feminista dos séculos XX e XXI", o que, afinal, foi seu importante legado.

10 Em Muzart (2003), a pesquisadora apresenta algumas pioneiras jornalistas e escritoras do Brasil, inclusive discutindo as posições da argentina aqui exilada Juana Paula Manso (de Noronha, nome de casada) e de sua antecessora, a menos comportada Maria Josefa Barreto Pereira Pinto. O estranhamento que movia Muzart e a fazia pesquisar as escritoras esquecidas é semelhante ao que nos move nas pesquisas sobre o similar apagamento das editoras, como a própria Zahidé.
} 
publicação. Sobre o processo editorial da Mulheres propriamente, Ramos nos conta:

Zahidé materializou em cada cor, em cada capa, em cada textura de papel, na escolha dos tipos e da editoração, em cada título, em cada nome próprio, em cada texto crítico, em cada prefácio, em cada apresentação, a história das mulheres. Exercitou durante toda a sua vida essa arte de cuidar: a capa, a oreIha, a contracapa, a autora, a apresentação, a biografia, o ensaio crítico, a bibliografia. 0 livro, para a Editora e para Zahidé, era visto como um espaço, um lugar, uma morada e, por essa razão, congregou inegavelmente um dos maiores e sólidos grupos de pesquisadoras brasileiras dos séculos XX eXXI, ao materializar e concretizar o investimento público e privado na pesquisa; ao disseminar o conhecimento; ao solidificar os estudos feministas e dar, assim, espaço e voz para a teoria e para a crítica feminista (RAMOS, 2016, p. 182).

Zahidé Muzart foi, portanto, o que Risolete Hellmann (2017) chamou de "editora voraz", entre muitas outras atribuições, como a fundação do Grupo de Trabalho Mulher na Literatura, da Associação Nacional de Pós-Graduação e Pesquisa em Letras e Linguistica (ANPOLL), em 1986, ou o evento Fazendo Gênero, nos anos de 1990. O projeto de resgate de 160 escritoras brasileiras do século XIX, que resultou na antologia em três volumes, e a criação da Editora Mulheres tiveram o efeito de, segundo Hellmann (2017), ajudar a constituir a crítica literária feminista no Brasil. Muzart (2014) admite suas inspirações:

Ao fundarmos essa editora, a inspiração nos veio das várias editoras feministas já existentes, desde muito tempo [...] na Europa, mas também no Chile, principalmente a francesa Des Femmes. Assim como as editoras feministas que nos precederam, também desejávamos tirar da marginalização os livros de mulheres do passado (apud HELLMANN, 2017, p. 7). ${ }^{11}$

Zahidé Muzart faleceu em 2015, aos 76 anos. Após isso, a Editora Mulheres foi vendida pelos herdeiros ${ }^{12}$. Segundo Hellmann (2017, p. 8), "já não cumpre o objetivo para o qual foi criada e mantida". De fato, quando visitamos o site, em 2019, o que encontramos é ainda uma empresa chamada Editora Mulheres, mas que se presta a outro tipo de serviço ou informação. Pesquisadoras do GT Mulher na Literatura mantiveram certo ritmo de publicações, empregando a marca da editora, no entanto a perda de força do selo é sensivel.

Se Zahidé Muzart estava preocupada em recontar a história da literatura brasileira, incluindo nossas escritoras de séculos passados, apagadas ou anarquivadas por uma narrativa histórica refratária ou cega à diversidade - e mesmo aos fatos, nós estamos aqui preocupados em que não aconteça o mesmo com as editoras mulheres brasileiras, às quais ocorre o mesmo tipo de apagamento e invisibilização que Muzart procurava enfrentar na literatura, em um gesto editorial performativo (SZPILBARG, 2018), com consciência do esforço que deveria fazer. Temos também ideia dos nossos esforços: dificuldades de encontrar vestígios, acervos, material biobibliográfico, publicações etc. Sequer o termo apagamento, amplamente empregado para esses casos, nos parece adequado, uma vez que apagar sucede alguma forma de existência. Muitas vezes, as escritoras e as editoras sequer tiveram existência na narrativa histórica, embora tenham tido de fato. Temos então qualificado como "editoras inenarradas", já que não têm sido descritas ou narradas, embora o possam e devam ser.

\section{Uma Senhora à testa da editora ${ }^{13}$}

O primeiro livro que veio à luz, em outubro de 1996, foi Mulheres ilustres do Brazil, de Inês Sabino, originalmente publicado em 1899. Considerado uma "prova de fogo" por Muzart (2004), o segundo Livro foi $A$ Silveirinha, de autoria de Júlia Lopes de Almeida, publicado em 1913, obra que trouxe uma série de desafios sobre decisões editoriais às editoras. A trinca de professoras aposentadas que deu vida inicial à Mulheres dissolveu-se em pouco tempo, mas Zahidé Muzart deu sequência aos

\footnotetext{
11 Além da casa francesa Des Femmes, havia também editoras feministas na Inglaterra e no Chile, respectivamente, Virago e Un cuarto propio. Pasko (2016) menciona também a brasileira Rosa dos Tempos.

12 Priscila Pasko (2016) trata da história da Editora Mulheres após a morte de Zahidé Muzart, comentando o extenso e relevante catálogo. No texto, traz depoimentos e relatos de colegas, amigos e parentes da editora, em especial do filho Pierre Muzart, que à época tentava dar continuidade ao empreendimento da mãe, com a ajuda da ex-revisora de textos da casa editorial, Gerusa Bondan, entrevistada no fim da matéria. 13 A frase é uma apropriação livre de parte do texto do editorial de Juana Paula Manso no Jornal das Senhoras, do qual foi fundadora, editora e redatora, em 1852. É, portanto, uma das pioneiras no Brasil, embora ela mesma fosse argentina. O texto original diz: "Ora pois, uma Senhora à testa da redação de um jornal! que bicho de sete cabeças será?" (MUZART, 2003).
} 
trabalhos da "microeditora", a despeito das forças contrárias: "Há sempre um sorriso condescendente para com uma microeditora que se chama Mulheres e ainda por cima dirigida por aposentadas, como se tudo fosse resumido em uma atividade terapêutica de terceira idade! Ora, pois..." (MUZART, 2004, p. 104).

Como uma iniciativa que poderia ser chamada, nos dias que correm, de "independente"14, a Editora Mulheres enfrentou todos os desafios de um empreendimento inicialmente amador, a começar pela aprendizagem das editoras em serviço, lidando com dificuldades no processo editorial e buscando capacitação em livros e manuais, conforme narra Muzart (2004). O duplo que aflige grande parte dos editores e editoras, isto é, a (in)conciliação entre cultura e comércio (DE DIEGO, 2015; BOURDIEU, 1999; THOMPSON, 2013), atingia a Mulheres, dando a Zahidé Muzart a chance de se posicionar como uma editora preocupada com as questões culturais, mais do que com o lucro financeiro. Dessa forma, ela opta por construir um catálogo relevante para a história literária e os estudos de gênero no Brasil, muitas vezes contra as dificuldades financeiras e de distribuição do negócio. Como editora de porte menor, era a própria Zahidé que tomava providências quanto à distribuição das obras, além de todos os cuidados do processo editorial, que corria sob a sua supervisão direta.

A Editora Mulheres investiu não apenas nas autoras nacionais, mas traduziu e publicou ensaios importantes de estudos feministas e de gênero, em um esforço grande em relação aos custos que isso significava para uma editora de pequeno porte. Em relação ao escoamento da produção, por exemplo, ela menciona a grande dificuldade com distribuidoras profissionais (das quais desistiu) e a bem-sucedida relação com feiras ${ }^{15}$ e eventos temáticos do feminismo e da literatura.

Conforme Muzart (2004), a Editora Mulheres publicava algumas séries, de forma a organizar as obras que lançava conforme algum critério: Romance (reedições de romances de escritoras do passado, como A Silveirinha, de Júlia Lopes de Almeida, e Úrsula, de Maria Firmina dos Reis, hoje ocupando espaços canônicos, ao que parece, e editados por vários selos contemporâneos), Ensaios (estudos sobre gênero, mas também a monumental antologia Escritoras brasileiras do século XIX, em três volumes, organizada pela própria Muzart), Poesia (edição e reedição de poetas, como As horas da minha alegria, de Izabel Brandão), Viagem (entre eles Peregrinações de uma pária, de Flora Tristán, e Diário de viagem ao redor do mundo, de Rose de Freycinet, ambas francesas) e Feministas (como Nísia Floresta, a primeira feminista do Brasil, de Constância Lima Duarte). Segundo Muzart (2004), a série de mais sucesso comercial era a Ensaios, com livros inclusive de mais de uma tiragem/impressão.

\section{3 "Cada livro é uma aventura": Zahidé Muzart e a produção da Editora Mulheres}

A Editora Mulheres publicou, em cerca de duas décadas, mais de uma centena de livros, em especial romances reeditados de escritoras do século XIX ou início do XX e ensaios sobre feminismo, obras que se tornaram referência na formação de gerações de pesquisadoras/es e mesmo de escritoras brasileiras. Schmidt e Ramos (2005) lembram-se do volume de mais de mil páginas sobre escritoras do século XIX chegado às suas mãos e publicado pela editora catarinense. Segundo as autoras, ficava ali explícita a

força de trabalho, manual e intelectual, de algumas pesquisadoras contemporâneas, somando a essa empreitada as escritoras (re) descobertas, a planejadora, a organizadora, as editoras, a prefaciadora: mulheres amarrando as pontas de dois séculos, integrando norte, sul, leste, oeste, as Américas (SCHMIDT; RAMOS, 2005, p. 219).

O trabalho de edição e reedição levado a cabo por Muzart confrontava - e afrontava - a narrativa hegemônica da história literária brasileira, deixando evidentes os "sequestros"

\footnotetext{
14 A questão da "independência" é prolífica, mas não nos deteremos nela aqui. O fato é que o modus operandi da Editora Mulheres em muito se assemelha ao de editoras independentes de hoje, a despeito de sua origem um tanto ligada à universidade. Sobre "independência" de editores, ver, por exemplo: Muniz Jr. (2010), Araújo (2011), Malumián e Winne (2013), Oliveira (2016).

15 O movimento das feiras e a sua relação com as pequenas editoras tem chamado atenção e vem sendo estudado com dedicação em vários países da América Latina nos dias de hoje. Ver, por exemplo, Muniz Jr. (2016) e Magalhães (2018).
} 
e, ao mesmo tempo, estremecendo os alicerces (nas palavras de Schmidt e Ramos) da tradição à qual estávamos acostumados. A palavra de ordem era "inclusão", a fim de trazer à superfície as escritoras asfixiadas pelo machismo estrutural e, ao mesmo tempo, evitar que o século $X X$ também tivesse de ser recontado, mais adiante. Sem modéstia, Schmidt e Ramos (2005, p. 220) afirmam que pesquisadoras e escritoras querem "entrar literalmente na História", consequência que Muzart e a sua casa parecem ter alcançado. $\mathrm{Na}$ definição da própria editora, tratava-se de um trabalho de "revolver escombros e garimpar entulhos" (SCHMIDT; RAMOS, 2005), ampliando e redimensionando a história literária de um país, mudando concepções, travando uma relação critica com a narrativa oficial. Uma obra como Escritoras Brasileiras do Século XIX, organizada e publicada pela Editora Mulheres, foi capaz de trazer e formar "um novo modo de olhar para a tradição literária brasileira" (SCHMIDT; RAMOS, 2005, p. 221), não apenas mostrando as escritoras de tempos passados, mas trazendo-as à luz, de fato, para serem lidas. A ideia de rasurar nossa história literária, conscientes de que se trata de uma luta simbólica e de efeitos lentos e de que "a participação das mulheres foi, quando não sistematicamente invisibilizada, expressamente objetada" (FANINI, 2018, p. 96), guiou as ações dessas mulheres (porque editar é ação), que compreendem, há tempos, que incorporar práticas relacionadas aos processos midiáticos é parte essencial do jogo (WOITOWICZ, 2012, p. 7).

A fim de alcançar seus claros objetivos, a Editora Mulheres compôs, ao longo dos anos, um catálogo notável de obras, com a sua linha editorial politicamente consciente, de ações firmes e bastante dependentes de um coletivo engajado. Segundo Pasko (2016), para além dos mais de cem livros, a casa editorial teve impacto na produção de conhecimento sobre nossa história literária, além de ter publicado autoras hoje consideradas de relevo, tais como Júlia Lopes de Almeida, de quem foram publicados pelo menos dez títulos. A Imagem 1, a seguir, mostra a capa e uma das páginas desse catálogo da casa editorial (2015), que traz também uma apresentação e uma carta de Muzart. Essa versão do documento é posterior à morte da editora e não traz todos os livros publicados pela casa.

Imagem 1 - Capa e uma página interna do catálogo da Editora Mulheres
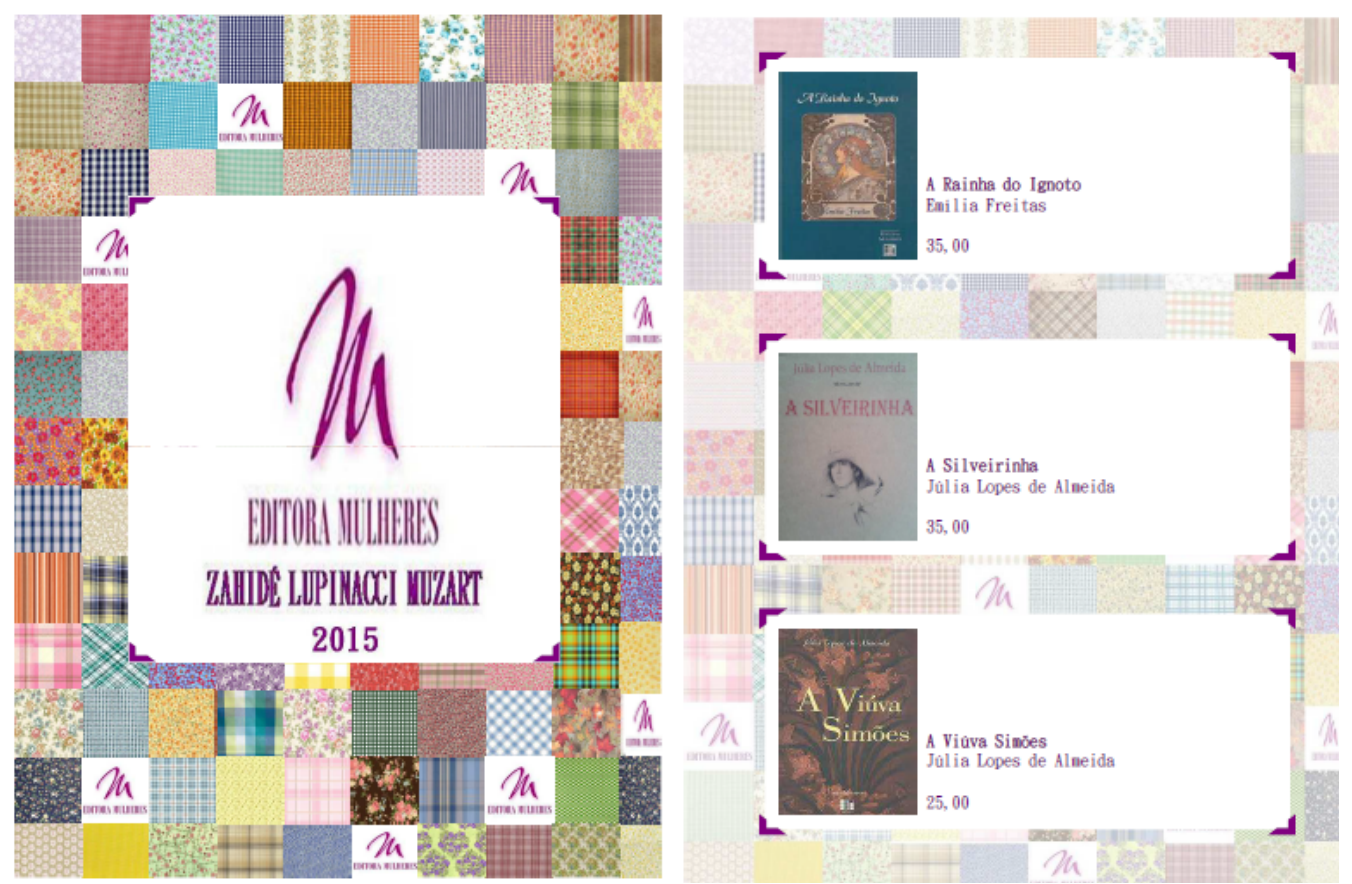

Fonte: Website Nonada. ${ }^{16}$

16 Disponivel em: http://www.nonada.com.br/wp-content/uploads/2015/11/Cat\%C3\%A1logo-novembro-2015.pdf. Acesso em: 20 de maio de 2019 
Em uma tentativa de contribuir para a narrativa sobre mulheres editoras no Brasil, além de tratarmos brevemente da própria Zahidé Muzart, empenhamos esforços em apresentar o catálogo de publicações da editora da maneira mais completa possivel. Conforme nossas possibilidades, apresentamos títulos, autoria ou organização, a série em que cada título foi publicado (sempre que possível), o ano de publicação que consta nas obras encontradas (impressas ou digitais) e algumas observações que podem importar. A extensão do quadro a seguir se justifica e explicita o trabalho de fôlego das editoras envolvidas. 0 que jamais se justifica é o relativo apagamento de uma casa editorial e da sua editora depois de um esforço notável como esse, por quase duas décadas e até o seu último suspiro.

Quadro 1 - Recomposição aproximativa do catálogo da Editora Mulheres desde sua fundação

\begin{tabular}{|c|c|c|c|c|}
\hline N. ${ }^{\circ}$ & TÍTULO & $\begin{array}{l}\text { Autoria ou } \\
\text { organização }\end{array}$ & Série & Observações \\
\hline \multirow[t]{2}{*}{ ค̆ } & Mulheres illustres do Brazil & Ignez Sabino & $\begin{array}{l}\text { Ensaios } \\
\text { (No catálogo de } \\
2011 \text {, esta obra pas- } \\
\text { sa a se enquadrar na } \\
\text { série Referências) }\end{array}$ & $\begin{array}{l}280 \text { páginas. Livro fundacional da Editora Mulhe- } \\
\text { res. Segundo Risolete Hellmann (2017), a obra } \\
\text { inaugural da Editora Mulheres, de Ignez Sabino, } \\
\text { foi "uma homenagem a uma extraordinária mulher } \\
\text { que reuniu as várias escritoras de seu tempo e pu- } \\
\text { blicou em livro com fotos e biografia". No catálogo } \\
\text { de } 2011 \text {, a obra está descrita como esgotada. }\end{array}$ \\
\hline & $\begin{array}{l}\text { Índice de dramaturgas brasi- } \\
\text { leiras do século XIX }\end{array}$ & $\begin{array}{l}\text { Valéria Andrade Sou- } \\
\text { to-Maior }\end{array}$ & $\begin{array}{l}\text { Ensaios/ } \\
\text { Referências }\end{array}$ & 56 páginas \\
\hline \multirow{5}{*}{ คे } & $\begin{array}{l}\text { Gênero sem fronteiras. Oito } \\
\text { olhares sobre mulheres e } \\
\text { relações de gênero }\end{array}$ & $\begin{array}{l}\text { Mônica Raisa Schpun } \\
\text { (org.) }\end{array}$ & Ensaios & $\begin{array}{l}208 \text { páginas. } \\
\text { No catálogo de 2011, a obra é descrita como } \\
\text { esgotada. }\end{array}$ \\
\hline & $\begin{array}{l}\text { Entre resistir e identificar-se: } \\
\text { para uma teoria da prática da } \\
\text { narrativa brasileira de autoria } \\
\text { feminina }\end{array}$ & Peggy Sharpe (org.) & Ensaios & $\begin{array}{l}200 \text { páginas. Coedição com a Editora da UFG } \\
\text { (Goiânia). }\end{array}$ \\
\hline & $\begin{array}{l}\text { A Silveirinha: crônica de } \\
\text { um verão }\end{array}$ & $\begin{array}{l}\text { Júlia Lopes de Al- } \\
\text { meida }\end{array}$ & Romance & 312 páginas. Introdução de Sylvia Paixão. \\
\hline & $\begin{array}{l}\text { Cintilações de uma alma } \\
\text { brasileira }\end{array}$ & Nisia Floresta & Ensaios & $\begin{array}{l}252 \text { páginas. O livro reúne cinco ensaios: O Brasil, } \\
\text { O Abismo sob as Flores da Civilização, A Mulher, } \\
\text { Viagem Magnética e Passeio ao Jardim de Luxem- } \\
\text { burgo. Coedição com a EDUNISC. Edição bilingue, } \\
\text { português/italiano. Introdução de Constância Lima } \\
\text { Duarte, trad. de Michele A. Vartulli. No catálogo de } \\
\text { 2011, a obra é descrita como esgotada. }\end{array}$ \\
\hline & D. Narcisa de Villar & $\begin{array}{l}\text { Ana Luisa de Azevedo } \\
\text { Castro }\end{array}$ & Romance & 140 páginas. Introdução de Zahidé Muzart. \\
\hline \multirow{4}{*}{$\stackrel{\infty}{\mathscr{g}}$} & Sorrisos e prantos & Rita Barém de Melo & Poesia & $\begin{array}{l}296 \text { páginas. No catálogo de 2011, a série se cha- } \\
\text { ma Poesia e Teatro. Atualização e introdução do } \\
\text { texto de Rita T. Schmidt. }\end{array}$ \\
\hline & $\begin{array}{l}\text { Masculino, feminino, plural: } \\
\text { gênero na interdisciplinaridade }\end{array}$ & $\begin{array}{l}\text { Joana Maria Pedro e Mi- } \\
\text { riam Pillar Grossi (orgs.) }\end{array}$ & Ensaios & $\begin{array}{l}320 \text { páginas. } 1^{a} \text { reimpressão em } 2000 \text {, segundo o } \\
\text { catálogo de } 2011 .\end{array}$ \\
\hline & $\begin{array}{l}\text { Itinerário de uma viagem à } \\
\text { Alemanha }\end{array}$ & Nísia Floresta & Viagens & $\begin{array}{l}216 \text { páginas. Texto do século XIX. Coedição com a } \\
\text { EDUNISC. }\end{array}$ \\
\hline & Lésbia & $\begin{array}{l}\text { Maria Benedita Bor- } \\
\text { mann (Délia) }\end{array}$ & Romance & $\begin{array}{l}264 \text { páginas. Romance. Atualização do texto, intro- } \\
\text { dução e notas por Norma Abreu Telles. }\end{array}$ \\
\hline
\end{tabular}




\begin{tabular}{lcc}
\hline${ }^{\circ}$ & Título & Autoria ou \\
organização & Série & Observações
\end{tabular}

Investigando a linguagem: ensaios em homenagem a Leonor Scliar-Cabral

Lutas do coração

Uma menina de Itajaí: crônicas

Falas de gênero: teorias, análises, leituras

คे

Escritoras brasileiras do século XIX: antologia, volume 1

Diário sua viagem ao Brasill 1842-1843

Baronesa E. De Langsdorff

Aphra Ben

Romance

uma história verdadeira

Júlia Lopes de Almeida

Romance

Ana Luísa de Azevedo Castro

Romance

Vera Queiroz

Ensaios

Flora Tristán (francesa) Viagens

Ana Chrystina Ve-

nancio Mignot, Maria

Refúgios do eu: educação, história e escrita autobiográfica
Helena Câmara Bastos, Ensaios

Maria Teresa Santos

Cunha (orgs.)
352 páginas.

No catálogo de 2011, a obra é descrita como esgotada.

336 páginas. Coedição com a EDUNISC. Atualização do texto, introdução e notas por Susan Canty Quinlan.

140 páginas

354 páginas

960 páginas. "Este livro partiu da constatação de uma ausência e de um esquecimento - as escritoras do século XIX, no Brasil, não estão presentes nas histórias da literatura e em muitos dicionários. Com o intuito de reverter tal situação, contextualizar, criticar e fazer circular uma produção que permanece desconhecida, uma equipe de pesquisadoras, com projeto integrado apoiado pelo CNPq, resgatou parte da obra de 53 brasileiras que escreveram no século XIX e elaborou esta Antologia, recuperando assim a história silenciada da mulher de letras no Brasil e contribuindo para escrever nossa história cultural." Houve reimpressão em 2000, segundo o catálogo de 2011

328 páginas. Coedição com a EDUNISC. Tradução de Patrícia Chittoni Ramos e Marco Antônio Toledo Neder. Prefácio de Miriam Lifchitz Moreira Leite. Relato de viagem ao Brasil por ocasião do casamento de S. A. R. o Príncipe de Joinville. Segundo o catálogo de 2011, a obra teve primeira reimpressão em 2000

128 páginas. Tradução e apresentação de Élvio Antônio Funck.

216 páginas. Coediç̃o com a EDUNISC. Atualização do texto, introdução e notas por Peggy Sharpe.

132 páginas, primeiro romance catarinense, publicado inicialmente em folhetim. (No catálogo de 2006, esta obra consta como publicada em 1997. Terá tido reedição?)

52 páginas

540 páginas. Texto do século XIX. Trad. de Maria Nilda Pessoa e Paula Berinson. Coedição com a EDUNISC.

240 páginas. Os textos reunidos neste livro, com perspectivas teóricas e questionamentos metodológicos, pretendem ampliar as possibilidades de utilização da escrita autobiográfica da História da Educação Brasileira. Do nordeste ao sul, mulheres potiguares, gaúchas, cariocas, catarinenses, mineiras, paulistas, em diferentes espaços, tempos e estações da vida, registraram suas formas de ver o mundo. Falam do desconhecido, do cotidiano, de lembranças familiares, de suas leituras, dos sonhos pessoais e profissionais, de política, da escola, de religiosidade, de inquietações com o futuro, da sexualidade e dos amores, revelando muitas vezes os mecanismos ocultos da educação familiar ou escolar que conformaram os gostos, as escolhas, os gestos, as sensibilidades. 


\begin{tabular}{|c|c|c|c|c|}
\hline N. ${ }^{\circ}$ & TÍTULO & $\begin{array}{l}\text { Autoria ou } \\
\text { organização }\end{array}$ & Série & Observações \\
\hline \multirow{2}{*}{ 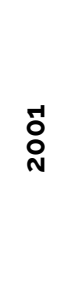 } & $\begin{array}{l}\text { O florete e a máscara: Josefina } \\
\text { Álvares de Azevedo, drama- } \\
\text { turga do século XIX }\end{array}$ & $\begin{array}{l}\text { Valéria Andrade Sou- } \\
\text { to-Maior }\end{array}$ & Ensaios & 160 páginas. \\
\hline & A luta & Carmen Dolores & Romance & $\begin{array}{l}190 \text { páginas. Coedição com a EDUNISC. Romance } \\
\text { de Carmen Dolores (pseudônimo de Emilia Mon- } \\
\text { corvo Bandeira de Melo). Fixação do texto, introdu- } \\
\text { ção e notas por Maria Angélica Guimarães Lopes. }\end{array}$ \\
\hline \multirow{3}{*}{$\stackrel{\text { N }}{\text { ON }}$} & $\begin{array}{l}\text { A cidadã paradoxal: as femi- } \\
\text { nistas francesas e os direitos } \\
\text { do homem }\end{array}$ & $\begin{array}{l}\text { Joan W. Scott (norte-a- } \\
\text { mericana) }\end{array}$ & Ensaios & $\begin{array}{l}312 \text { páginas. Trad. de Élvio A. Funck, apresentação } \\
\text { de Miriam Pillar Grossi. } \\
\text { No catálogo de } 2011 \text {, a obra é descrita como esgotada }\end{array}$ \\
\hline & Uma colônia no Brasil & Mme. Van Langendonk & Viagens & $\begin{array}{l}168 \text { páginas. A primeira edição é de 1862. Tradução } \\
\text { de Paula Berinson. Introdução de Augusto Meyer. }\end{array}$ \\
\hline & $\begin{array}{l}\text { Cartas Nísia Floresta \& Augus- } \\
\text { te Comte }\end{array}$ & $\begin{array}{l}\text { Constância Lima } \\
\text { Duarte (Org.) }\end{array}$ & Cartas e memórias & $\begin{array}{l}104 \text { páginas. Tradução de Paula Berinson e } \\
\text { Milton Lemos. }\end{array}$ \\
\hline \multirow{6}{*}{$\stackrel{m}{\stackrel{m}{N}}$} & $\begin{array}{l}\text { O tempo e o rastro: da viagem } \\
\text { e sua imagem }\end{array}$ & Nara Araújo (cubana) & Ensaios & 274 páginas. Trad. de Eliane Tejera Lisboa. \\
\hline & $\begin{array}{l}\text { Uma voz ao sul: os versos de } \\
\text { Maria Clemência da Silveira } \\
\text { Sampaio }\end{array}$ & $\begin{array}{l}\text { Maria Eunice Moreira } \\
\text { (org.) }\end{array}$ & Poesia & $\begin{array}{l}112 \text { páginas. Edição ilustrada. Atualização e intro- } \\
\text { dução da organizadora. }\end{array}$ \\
\hline & $\begin{array}{l}\text { Refazendo nós: ensaios sobre } \\
\text { mulher e literatura }\end{array}$ & $\begin{array}{l}\text { Izabel Brandão e Zahi- } \\
\text { dé L. Muzart (orgs.) }\end{array}$ & Ensaios & $\begin{array}{l}552 \text { páginas. Coedição com a EDUNISC. "Este livro é } \\
\text { produto das reuniões do Grupo de Trabalho 'A mulher } \\
\text { na literatura' da ANPOLL e traz os ensaios inéditos } \\
\text { apresentados nos encontros do grupo em Niterói e } \\
\text { em Gramado. O livro foi dividido em cinco partes que, } \\
\text { ao buscar dar uma unidade aos vários artigos, tam- } \\
\text { bém contempla as linhas temáticas das pesquisas } \\
\text { do grupo. Este livro é testemunha do amplo debate } \\
\text { ocorrido no último encontro e da rica diversidade de } \\
\text { expectativas e preocupações que o marcou." }\end{array}$ \\
\hline & $\begin{array}{l}\text { Emancipação do sexo femi- } \\
\text { nino: a luta pelos direitos da } \\
\text { mulher no Brasil, } 1850-1940\end{array}$ & $\begin{array}{l}\text { June Edith Hahner } \\
\text { (norte-americana) }\end{array}$ & Ensaios & $\begin{array}{l}448 \text { páginas. Trad. de Eliane Tejera Lisboa, apre- } \\
\text { sentação de Joana Maria Pedro. Coedição com a } \\
\text { EDUNISC. }\end{array}$ \\
\hline & A falência & $\begin{array}{l}\text { Júlia Lopes de } \\
\text { Almeida }\end{array}$ & Romance & $\begin{array}{l}376 \text { páginas. Coedição com a EDUNISC. Introdução } \\
\text { e atualização do texto por Elódia Xavier. }\end{array}$ \\
\hline & A rainha do Ignoto & Emilia Freitas & Romance & $\begin{array}{l}432 \text { páginas. Coedição com a EDUNISC. Romance } \\
\text { psicológico. Atualização do texto, introdução e } \\
\text { notas por Constância Lima Duarte. }\end{array}$ \\
\hline
\end{tabular}




\section{$10 / 18$}

Letrônica, Porto Alegre, v. 13, n. 1, p. 1-18, jan.-mar. 2020 | e-34581

\section{N. ${ }^{\circ}$ \\ TíTULO \\ Pilares narrativos: a construção do eu na prosa contemporânea}

\section{Autoria ou organização}

Série

Ensaios de oito romancistas brasileiras

Poéticas e políticas feministas e Simone Pereira Schmidt (orgs.)

Ensaios

Maria Regina Azevedo

Gênero, cultura e poder isboa e Sonia Weidner Maluf (orgs.)

Carmen Sílvia Moraes Rial e Maria Juracy Filgueiras Toneli (orgs.)

Zahidé L. Muzart (org.)

Ensaios

Mara Coelho de Souza Lago, Miriam Pillar Grossi, Cristina Tavares da Costa Rocha, Olga Regina Zigelli Garcia e Tito Sena (orgs.) sexualidades, religiões

Escritoras brasileiras do século XIX: antologia, volume 2

Interdisciplinaridade em

Ensaios

Ensaios

Ensaios

Maria Firmina dos Reis

Romance

224 páginas. Apresentação de Susan C. Quinlan. No catálogo de 2011, a obra é descrita como esgotada.

260 páginas. O livro é resultado de uma seleção de trabalhos apresentados em diversas mesas-redondas do Encontro Internacional Fazendo Gênero 5 - Feminismo Como Política, realizado no período de 8 a 11 de outubro de 2002, na Universidade Federal de Santa Catarina.

160 páginas

200 páginas.

284 páginas

288 páginas. Coedição com a Editora PUC Minas Posfácio de Eduardo de Assis Duarte. Inclui o conto "A escrava". Reeditado em 2009 como edição comemorativa dos 150 anos da $1^{\text {a }}$ edição. Segundo o catálogo de 2011, houve reimpressão em 2009.

Villa Rica: Um tempo feliz

Marcar diferenças, cruzar fronteiras

Resgates e ressonâncias: Mariana Coelho

Maria Lacerda de Moura: uma feminista utópica

N Nisia Floresta, a primeira feminista do Brasil

Elas escrevem o épico

Gênero em discursos da midia

Mulheres em ação: práticas discursivas, práticas políticas
Ruth Laus (coord.)

Jean Franco (britânica)

Rosana Cássia Kamita

Miriam Lifchitz Moreira Leite

Constância Lima

Duarte

Christina Ramalho

Susana Bornéo Funk e Nara Widholzer (Orgs.)

Tania Navarro Swain e Diva do Couto Gontijo Muniz (Orgs.)
453 páginas.

364 páginas, coedição com a Editora PUC Minas. Trad. de Alai Garcia Diniz.

184 páginas

364 páginas. Coedição com a EDUNISC. Introdução de Miriam Lifchitz Moreira Leite. Série Feministas.

144 páginas. vol. 1

188 páginas. Coedição com a EDUNISC. Prefácio de Simone Caputo Gomes. No catálogo de 2011, a obra é descrita como esgotada.

336 páginas. No catálogo de 2011, a obra é descrita como esgotada.

Ensaios
360 páginas. No catálogo de 2011, a obra é descrita como esgotada. 


\begin{tabular}{|c|c|c|c|c|}
\hline N. ${ }^{\circ}$ & TÍTULO & $\begin{array}{c}\text { Autoria ou } \\
\text { organização }\end{array}$ & Série & Observações \\
\hline
\end{tabular}

Brasileiras notáveis: uma abordagem radiofônica

A décima carta / Laus, apenas memórias literárias

Entre o estético e o político: a mulher nas literaturas clássicas e vernáculas

Entre o estético e o político: a mulher nas literaturas de linguas estrangeiras

Memórias de uma feminista

Depoimentos: trinta anos de pesquisas feministas brasileiras sobre violência

Bertha Lutz

Gênero e violência: pesquisas acadêmicas brasileiras (1975-2005)

Maternidade e feminismo: diálogos interdisciplinares

Vozes em dissonância: Mulheres, memórias e nação

Os papéis do coronel

Sedução e heroismo: imaginação de mulher entre a República das Letras e a Belle Époque (1884-1911)

Que corpo é esse? O corpo no imaginário feminino

\section{Gênero em movimento: novos} olhares, muitos lugares

Leituras em rede: gênero e preconceito

Entre saias justas e jogos de cintura

Divórcio?

Memórias de Marta

A construção dos corpos: perspectivas feministas
Noemi Flores

Ruth Laus (org.)

Maria Conceição Monteiro e Tereza Marques de Oliveira Lima (orgs.

Maria Conceição Monteiro e Tereza Marques de Oliveira Lima (orgs.)

Madeleine Pelletier (francesa)

Miriam Pillar Grossi, Luzinete Simões Minella e Rozeli Porto (orgs.)

Rachel Soihet

Miriam Pillar Grossi Luzinete Simões Minella e Juliana Cavilha Mendes Losso

Cristina Stevens (Org)

Ensaios

Kátia da Costa Bezerra

Ensaios

Harry Laus

Regina Rogério Felix

Ensaios

Elódia Xavier

Ensaios

Cristiani Bereta da Silva, Gláucia de Oliveira Assis e Rosana Cássia Kamita (orgs.)

Cristina Scheibe Wolff Marlene de Fáveri e Tânia Regina Oliveira Ramos

Soraya Resende Fleischer e Alinne Bonett

Andradina América de Andrade e Oliveira

Júlia Lopes de Almeida

Romance

Cristina Stevens e Tânia Navarro Swain (Orgs.)

Ensaios
Ensaios/

Referências

296 páginas. Coedição com a EDUNISC.

Cartas e memórias

256 páginas, ilustrado.

352 páginas. Primeiro volume reunindo trabalhos apresentados no Seminário "Mulher e Literatura", em 2005, no Rio de Janeiro.

392 páginas. Segundo volume reunindo trabalhos apresentados no Seminário "Mulher e Literatura", em 2005, no Rio de Janeiro.

80 páginas. Tradução de Paula Berinson, prefácio de Joan W. Scott, apresentação de Joana Maria Pedro, organização de Zahidé Lupinacci Muzart.

Gênero e violência 384 páginas.

312 páginas. Coedição com a EDUNISC. No catálogo de 2011, a obra aparece com o título $O$ feminismo tático de Bertha Lutz.

Gênero e violência 96 páginas.

254 páginas. Coedição com a EDUNISC. Apresentação de Diva do Couto Gontijo Muniz. No catálogo de 2011, a obra é descrita como esgotada.

256 páginas

169 páginas. Edição bilíngue, português/francês.

134 páginas (No catálogo de 2006, o livro era anunciado com o título A modernidade na literatura brasileira escrita por mulheres: Maria Benedita Bormann e Emilia Bandeira de Melo - 1884 a 1911)

No catálogo de 2011 não informa número de páginas.

344 páginas. Textos resultantes dos diálogos

estabelecidos durante o Seminário Internacional Fazendo Gênero 7, realizado em 2006, na Universidade Federal de Santa Catarina.

520 páginas

370 páginas. O livro é resultado das experiências de 12 antropólogas que falam sobre a experiência de seus trabalhos de campo na área da antropologia.

176 páginas. Organização e texto biobibliográfico de Hilda Agnes Hübner Flores. Coedição com ALFRS/EDIPLAT, de Porto Alegre.

Introdução de Rosane Salomoni.

308 páginas, ilustrado. Trabalhos apresentados no Simpósio Fazendo Gênero, 2006. 


\begin{tabular}{lcc}
\hline N. & Autoria ou & Sulo \\
organização & Observações \\
\hline
\end{tabular}

Mulheres em Letras: antologia Constância Lima Duarde escritoras mineiras

Uma casa sem cor

Uma escritora na periferia do

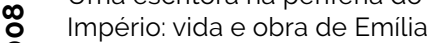
Freitas

Maria Ribeiro: teatro quase completo

Peregrinas de outrora: viajantes latino-americanas no século XIX

$$
\text { te (org.) }
$$

Zahidé Lupinacci Muzart

Alcilene Cavalcante

Stella Maris Scatena Franco
Ensaios

Valéria Andrade (org.) Teatro

Ensaios 304 páginas. Coedição com a EDUNISC.

389 páginas

206 páginas. Apresentação de Constância Lima Duarte.

174 páginas. Anunciada no catálogo de 2006.
Trajetória educacional de mulheres em assentamentos de reforma agrária na região Tocantina-MA

Transparências da memória Estórias de opressão - Diálogos com a poesia brasileira contemporânea de autoria feminina

Pelos caminhos do mundo

Narrar processos: traumas da violência doméstica e possibilidades para a educação

Narrar processos: tramas da a violência doméstica e possibilidades para a educação

Em nome da mãe - o não reconhecimento paterno no Brasil

Escritoras brasileiras do século XIX: antologia, volume 3

Dicionário de escritoras portuguesas: das origens à atualidade
Elisângela Santos de Amorim

Ensaios

175 páginas

Angélica Soares

Ensaios

200 páginas

Maria Luiza de Carvalho Armando

Poesia

189 páginas (folhas soltas, dentro de uma caixa, inclui CD).

Edla Eggert

Gêneros e violência

88 páginas.

Edla Eggert

Gênero e violência

87 páginas

Ana Liési Thurler

Ensaios

368 páginas

Zahidé L. Muzart (org.)

Ensaios/

Referências

Conceição Flores,

Constância Lima Duarte e Zenóbia Collares Moreira (orgs.) 


\begin{tabular}{|c|c|c|}
\hline N. ${ }^{\circ}$ & TÍTULO & $\begin{array}{c}\text { Autoria ou } \\
\text { organização }\end{array}$ \\
\hline
\end{tabular}

Leituras de resistência: corpo, $\quad$ nquist, Clair Castilhos

violência e poder, vol. 1

Coelho, Mara Coelho

de Souza Lago e Teresa

Kleba Lisboa (orgs.)

Carmen Susana Tor-

nquist, Clair Castilhos

Leituras de resistência: corpo,

:

violência e poder, vol. 2

Coreografias do feminino

A familia Medeiros

Uma casa sem cor

Versos para Pituquim - com pó de pirlimpimpim

Práticas pedagógicas e emancipação: gênero e diversidade na escola

Mulher e literatura: 25 anos, Raizes e rumos

Ecos do Oriente: o relato de viagem na literatura brasileira contemporânea

Roteiros inconscientes

Contos antigos: 1947 a 1949

Maria Amorim Ferrara

Parry Scott, Rosineide Cordeiro e Marilda Aparecida de Menezes (orgs.)

Gênero e geração em contextos rurais

Gênero, Feminismos e Ditaduras no Cone Sul

Diversidades: dimensões de gênero e sexualidade

Estudos interdisciplinados: gênero, feminismo, sexualidade

O perdão

Coelho, Mara Coelho

de Souza Lago e Teresa

Kleba Lisboa (orgs.)

Carla Rodrigues

Luzinete Simoes Mi-

nella e Carla Giovana

Cabral

Miriam Lifchitz Moreira Leite

Joana Maria Pedro e Cristina Scheibe Wolff (orgs.)

Carmen Rial, Joana Maria Pedro e Sílvia Maria Fávero Arend (orgs)

Miriam Pillar Grossi,

Mara Coelho de Souza

Lago e Adriano Henri-

que Nuernberg (orgs.)

Andradina América de
Ensaios

528 páginas. "Os dezoito artigos que compõem o primeiro volume da publicação são resultados do evento "Fazendo Gênero" da Universidade Federa de Santa Catarina, em 2008, que teve por eixo corpo, violência e poder."

Ensaios

440 páginas

Ensaios

136 páginas

496 páginas. Anunciado no catálogo de 2006

Infanto-juvenil

Sem número de páginas.

Infanto-juvenil

Sem número de páginas.

Ensaios

288 páginas

Cristina Stevens (Org.) Ensaios

280 páginas com capítulos sobre os 25 anos do GT da Anpoll.

Ensaios

224 páginas

Romance

208 páginas. No catálogo de 2011, a série leva o nome Romance/Narrativas.

120 páginas. O livro reúne dez contos inéditos da escritora nascida em Minas Gerais, Maria Guiomar Pires de Amorim (1898-1974), em narrativas escritas na primeira metade do século XX, publicados por incentivo e desejo da familia da escritora.

Ensaios

480 páginas.

Ensaios

296 páginas. Livro não comercializado. Financiado pela Secretaria das Mulheres.

432 páginas (disponível em pdf: https://sexualida-

Ensaios diversidadedimensoes)

Andrade e Oliveira
310 paginas. Romance de 1910. Organização e introdução de Rita Terezinha Schmidt, fixação do texto e notas de Rosane Saint-Denis Salomoni e Anselmo Peres Alós. 


\begin{tabular}{|c|c|}
\hline $\mathbf{N} .^{\circ}$ & TÍTULO \\
\hline & Dicionário de mulheres \\
\hline & $\begin{array}{l}\text { Histórias de abandono: infân- } \\
\text { cia e justiça no Brasil (década } \\
\text { de 1930) }\end{array}$ \\
\hline & $\begin{array}{l}\text { Diásporas, mobilidades e } \\
\text { migrações }\end{array}$ \\
\hline & $\begin{array}{l}\text { A invenção da solteirona: } \\
\text { conjugalidade moderna e } \\
\text { terror moral }\end{array}$ \\
\hline 곡 & $\begin{array}{l}\text { A escritura no feminino: } \\
\text { aproximações }\end{array}$ \\
\hline
\end{tabular}

O pai está esperando? - Políticas públicas de saúde para a gravidez na adolescência

Resistências, Gênero e Feminismos contra as ditaduras no Cone Sul

Fronteiras de gênero

O legado ficcional de Lúcia Miguel Pereira: escritos da tradição

De Criciúma para o mundo: rearranjos familiares dos novos migrantes brasileiros

Escritoras de ontem e de hoje: antologia

Tráfico de mulheres na Amazônia

Casamento e sexualidade: a construção das diferenças

A casa na ficção de autoria feminina

Gênero e trabalho: diversidade de experiências em educação e comunidades tradicionais

\section{Autoria ou organização}

Hilda Agnes Hübner Flores

Sílvia Maria Fávero Arend

Silvia Maria Fávero Arend, Carmen Sílvia de Moraes Rial, Joana Maria Pedro

Cláudia Maia

Aline Alves Arruda, Ana Caroline Barreto Neves, Constância Lima Duarte, Kelen Benfenatti Paiva e Maria do Rosário Alves Pereira (orgs.)

Maria Juracy Filgueiras Toneli, Benedito Medrado, Jorge Lyra, Zeidi Araujo Trindade

Joana Maria Pedro, Cristina Scheibe Wolff e Ana Veiga (orgs.)

Joana Maria Pedro. Sílvia Maria Fávero Arend e Carmen Sílvia Moraes Rial (orgs.)

Edwirgens Aparecida Ribeiro Lopes de Almeida

Gláucia de Oliveira Assis

Constância Lima Duarte, Elisângela Aparecida Lopes, Maria do Socorro Vieira Coelho, Imaculada Nascimento, Maria Inês de Moraes Marreco e Maria Lúcia Barbosa (Orgs.)

Iraildes Caldas Torres e Márcia Maria de Oliveira

Helen Ulhôa Pimentel

Elódia Xavier

Maria do Rosário de Fátima Andrade Leitão e Maria Helena Santana Cruz (orgs.)

\section{Série}

Observações
798 páginas, dicionário biográfico de mulheres (também escritoras).

Ensaios

356 páginas

326 páginas

Ensaios

Sem número de páginas.

Ensaios

425 páginas

Ensaio

240 páginas

432 páginas. Os estudos aqui presentes são oriundos das mesas redondas apresentadas no Colóquio Internacional Gênero, Feminismos e Ditaduras no Cone Sul, realizado na Universidade Federal de Santa Catarina, em 2009.

279 páginas

Ensaios

256 páginas

Ensaios

338 páginas

416 páginas. Ensaios sobre escritoras específicas,

Ensaios . antologia. Série Ensaios. Coedição com FAPEMIG/ CNPq/Grupo Mulheres em Letras.

Ensaios

128 páginas.

Ensaios

208 páginas. Prefácio de Luciano Figueiredo.

Ensaios

176 páginas. Prefácio de Ana Maria Machado.

239 páginas. "Os textos desde livro integram a programação do Seminário Internacional Fazendo Género 9: Diásporas, Diversidades, Deslocamentos, realizado em 2010 na Universidade Federal de Santa Catarina

Os trabalhos foram apresentados no Simpósio 17. Diversidade de experiências de gênero, trabalho e educação: comunidades tradicionais (pescadoras/es, quilombolas, indigenas, agricultoras/es familiares)". 


\begin{tabular}{|c|c|}
\hline N. ${ }^{\circ}$ & TÍTULO \\
\hline & $\begin{array}{l}\text { Diário de viagem ao redor do } \\
\text { mundo }\end{array}$ \\
\hline & Texto e interação na escola \\
\hline & Ânsia eterna \\
\hline & $\begin{array}{l}\text { Sexualidades, estatisticas } \\
\text { e normalidades: a persona } \\
\text { numerabilis nos relatórios Kin- } \\
\text { sey, Masters \& Johnson e Hite }\end{array}$ \\
\hline & As horas da minha alegria \\
\hline & $\begin{array}{l}\text { A letra, o corpo e o desejo: } \\
\text { masculinidades subversivas } \\
\text { no romance latino-americano }\end{array}$ \\
\hline 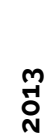 & $\begin{array}{l}\text { Vivência escrita: a crônica } \\
\text { de Rachel de Queiroz em } 0 \\
\text { Cruzeiro - Anos } 50\end{array}$ \\
\hline
\end{tabular}

Becos da memória

Pássaro tonto

Mulher no espelho

Impregnações na floresta: poemas amazônicos

Por trás do véu e da espada: o "disfarce" subjacente à representação das personagens cervantinas

O erotismo como ruptura na ficção brasileira de autoria feminina: um estudo de Clarice Lispector, Hilda Hilst e Fernanda Young

Arquivos femininos: literatura, valores, sentidos

Maria Wilker

Poemas para a amiga e outros dizeres

Mistérios del Plata - romance histórico contemporâneo

Aurélia

O regionalismo na literatura e o "mito do gaúcho" no extremo sul do Brasil: Simões Lopes Neto. Tomo I: O Rio Grande do Sul e o "mito do gaúcho" (panorama da problemática)

O regionalismo na literatura e o "mito do gaúcho" no extremo sul do Brasil: Simões Lopes Neto. Tomo II: Simões Lopes Neto e o "mito do gaúcho" (análise textual e intertextual)

\section{Autoria ou \\ Série \\ Observações}

Rose de Freycinet

(francesa)

Viagens

Luciene Fontão

Júlia Lopes de Almeida

Tito Sena

Ensaios

Izabel Brandão

Poesia

Anselmo Peres Alós

Ensaios

Cecilia Cunha

Conceição Evaristo

Júlia Lopes de Al-

meida

Helena Parente Cunha

Helena Parente Cunha

Edwirgens A. R. Lopes

de Almeida

Luciana Borges

Romance
272 páginas. Trad. de Rosa Alice Mosimann. Coedição com a Edunisc.

128 páginas

247 páginas. Contos. Organização, atualização do texto e introdução por Zahidé Lupinacci Muzart.

284 páginas. Prefácio de Mara Lago e Miriam Grossi.

128 páginas. Prefácio de Helena Parente Cunha.

240 páginas. Prefácio de Sônia Weidner Maluf.

470 páginas

270 páginas. Prefácio de Simone Pereira Schmidt posfácio de Maria Nazareth Soares Fonseca. O catálogo de 2013 aponta como $2^{a}$ edição.

223 páginas. Romance. Organização e introdução de Zahidé Lupinacci Muzart, apontamentos biográficos de Rosane Saint-Denis Salomoni.

O catálogo de 2013 aponta como décima edição.

Poesia e Teatro

90 páginas.

243 páginas. Introdução de Maria Augusta da Costa Vieira

398 páginas. Prefácio de Pedro Carlos

Louzada Fonseca.
Constância Lima Duar-

te, Claudia Maia, Laile

Ribeiro de Abreu, lara

Christina Silva Barroca

e Maria de Fátima Mo-

reira Peres (Orgs.)

Suzana Albornoz

Romance

Helena Parente Cunha

Juana Manso

Maria Benedita Bormann (Délia)

Maria Luiza de Carva-

tho Armando

Maria Luiza de Carvatho Armando

Romance

Romance
520 páginas com textos apresentados no V Colóquio Mulheres em Letras. Série Ensaios.

282 páginas. Primeira edição em 1983 pela Fundação Catarinense de Cultura em convênio com a IOESC.

93 páginas. Prefácio de Lúcia Zolin, apresentação de Maximiliano Torres.

311 páginas.

173 páginas. Organização, introdução e notas por Norma Telles.

414 páginas. I. Anexos da tese original. II. Apêndices da edição brasileira (CD-ROM). Trad. de Suzana Guerra Albornoz.

476 páginas. Trad. de Suzana Guerra Albornoz. 


\begin{tabular}{lcc}
\hline N. & Título & Autoria ou \\
organização & Série & Observações \\
\hline
\end{tabular}

O regionalismo na literatura e o "mito do gaúcho" no extremo sul do Brasil: Simões Lopes Neto. Tomo III: Uma cultura amea-

Maria Luiza de Carvalho Armando 338 páginas. Trad. de Suzana Guerra Albornoz. çada? (proposição para uma

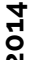
análise histórico-sociológica)
Almas complexas
Carmen Dolores

Correio da roça

Júlia Lopes de Almeida
Romance
182 páginas. Contos. Organização, estabelecimento do texto, ensaio introdutório, bibliografia, cronologia e notas por Risolete Maria Hellmann.

260 páginas. Organização, estabelecimento do texto e orelhas por Zahidé Lupinacci Muzart. Introdução de Ana Helena Cizotto Belline.
Eliezer Moreira e Noemi Flores

Suzana Albornoz

Júlia Lopes de Almeida
Romance

Júlia Lopes de Almeida
Romance

Ensaios
90 páginas

110 páginas. Prefácio de Carmem Maria Serralta, ilustrações de Rachel Damboriarena.

398 páginas. Organização e introdução por Rita Terezinha Schmidt, estabelecimento do texto por Kauan Negri e Rafael Daiane da Rocha, apresentação de Rafael Eisinger Guimarães.

208 páginas. Organização, estabelecimento do texto e introdução de Zahidé Lupinacci Muzart; biografia de D. Júlia Margarida Lopes de Almeida; apresentação de Norma Telles.

552 páginas, ilustrado
História das mulheres e do
gênero em Minas Gerais

Antropologia, gênero e edu-

cação em Santa Catarina

공

Traduções da cultura: perspectivas criticas feministas (1970-2010)

\section{Cláudia Maia e Vera} Lúcia Puga (org.)
277 páginas. Coedição com Gráfica Copiart Editora (Tubarão - SC). Disponivel em pdf: http://nigs.ufsc. br/files/2017/og/Livro-Antropologia-genero-e-educacao-vers\%C3\%A30-digital.pdf)

840 páginas. Coedição com EDUFAL e UFSC.
Izabel Brandão, Ildney

Cavalcanti, Claudia

de Lima Costa e Ana

Cecilia A. Lima (orgs.)

Tânia Welter, Miriam

Pillar Grossi e Mareli

Eliane Graupe (orgs.)

Maria Benedita Bormann (Délia)
Informação indisponivel.

I. I.* Duas irmãs

Fonte: Elaborado pelos autores com base na pesquisa ${ }^{17}$.

* Informação indisponivel.

* No catálogo de 2006, foram anunciadas as obras (provavelmente não editadas) Diálogos no umbral, de Nara Araújo, com tradução de Eliane Lisbôa; Cartas a sua filha, de Calamity Jane, com tradução de Paula Berinson; Francisca Senhorinha da Mota Diniz, de Aparecida Maria Nunes; Edith Mendes da Gama e Abreu, de Maria da Conceição Pinheiro Araújo; Três narrativas, Délia (Maria Benedita Bormann), com introdução e atualização do texto por Norma Telles. Na série Viagens, Uma parisiense no Brasil, de Mme. Toussaint-Samson, com introdução de June E. Hahner e tradução de Paula Berinson. No catálogo de 2013, são anunciados os livros As horas da minha alegria, de Izabel Brandão, efetivamente publicado em 2013, e Vivência escrita: A crônica de Rachel de Queiroz em O Cruzeiro - Anos 50, de Cecilia Cunha, não encontrado por nós. Pelo catálogo recomposto, é possivel visualizar o ritmo de publicações da editora, sendo os anos de 2000 os de sua produção mais numerosa, com parcerias importantes, em especial com a editora da Universidade de Santa Cruz do Sul (Unisc). Também é possivel divisar as redes de pesquisadoras e de escritoras, críticas, tradutoras e prefaciadoras que auxiliavam na condição deste projeto editorial eminentemente político e informado.

\footnotetext{
17 Agradecemos à professora Constância Lima Duarte, por ceder os catálogos de 2006, 2011 e 2013 de seu arquivo pessoal, e à professora Sônia Weidner Maluf, pela indicação do catálogo de 2015 na web. Este também foi o ano do falecimento de Zahidé Muzart, o que desacelerou sensivelmente a produção da Editora Mulheres. Gratos também a Eduardo Ribeiro Rocha pelo auxilio nas conferências e nos cotejamentos.
} 


\section{Considerações finais}

O objetivo de completar lacunas ou mesmo de rasurar a história editorial brasileira (normalmente contada por homens e sobre figuras masculinas importantes para a edição no País), traçando uma cartografia mais justa dos acontecimentos, parece ser comum a muitas pesquisadoras. Tais lacunas dizem respeito à narrativa sobre mulheres que ocuparam e ocupam posições relevantes e mesmo pioneiras na publicação, em especial, de literatura na cena nacional e, por extensão, latino-americana.

As mulheres editoras, embora sejam plenamente narráveis, permanecem em grande parte inenarradas, sendo o interesse por elas e mesmo por escritoras algo relativamente recente no Brasil (da década de 1980 em diante). Neste trabalho, apresentamos uma breve - e assumidamente insuficiente - narrativa sobre a pioneira Zahidé Muzart, professora atuante desde o estado de Santa Catarina, na região Sul do Brasil, conhecida, entre muitas outras coisas, por fundar e dirigir, com colaboradores/as, a casa editorial Mulheres, de viés explicitamente feminista. Com essa característica, o selo evidentemente se preocupou em constituir um catálogo de obras também escritas por mulheres, conforme recomposição aqui apresentada, inclusive com lacunas e oscilações dos próprios catálogos da editora.

A omissão do nome dessa editora pioneira, entre outras, da linha do tempo da história editorial brasileira caracteriza-se como apagamento inaceitável para uma justa narrativa sobre a edição no País e no continente. Esperamos ter contribuido para que a narrativa sobre Zahidé Muzart e a Editora Mulheres, uma entre tantas editoras de relevo no Brasil, seja considerada em pé de igualdade em nossa história da edição e do livro, dado que o seu catálogo e a sua força performativa como editora são, hoje, fatos inquestionáveis, com efeitos sentidos nas publicações atuais (revistas, ampliadas, comentadas) de autoras de séculos passados.

\section{Referências}

ARAÚJO, Pablo Guimarães de. Edições independentes e práticas editoriais: novas possibilidades de publicação do impresso ao digital. In: CONGRESSO BRASILEIRO DE CIÊNCIAS DA COMUNICAÇÃO, 26, 2 a 6 de set. 2011, Recife. Anais eletrônicos [...]. Recife: Intercom, 2011. Disponivel em: http://Www. intercom.org.br/papers/nacionais/2011/ resumos/ R6-2032-1.pdf. Acesso em: 20 jun. 2019. https://doi. org/10.1590/s1809-58442013000200005

BOURDIEU, Pierre. Une révolution conservatrice dans l'édition. Actes de la Recherche en Sciences Sociales, Paris, v. 126-127, p. 3-28, mars. 1999. https:// doi.org/10.3406/arss.1999.3278

COSTA, Cláudia de Lima. As publicações feministas e a política transnacional da tradução: reflexões do campo. Estudos Feministas, Florianópolis, v. 11, n. 1 , p. 254-264, jan./jun. 2003. https://doi.org/10.1590/ s0104-026×2003000100017

DE DIEGO, José Luis. La otra cara de Jano. Una mirada crítica sobre el libro y la edición. Ciudad Autónoma de Buenos Aires: Ampersand, 2015. https://doi. org/10.14409/tb.v1i5.6645

FALECE a professora aposentada Zahidé Lupinacci Muzart. In: Noticias da UFSC. Florianópolis: UFSC, 2015. 28 out. 2015. Disponivel em: https://noticias. ufsc.br/2015/10/falece-a-professora-aposentada-zahide-lupinacci-muzart/. Acesso em: 28 out. 2015 https://doi.org/10.1590/1805-9584-2016v24n1p181

FANINI, Michele Asmar. Júlia Lopes de Almeida em cena: notas sobre seu arquivo pessoal e seu teatro inédito. Revista do Instituto de Estudos Brasileiros, São Paulo, n. 71, p. 95-114, dez. 2018. https://doi. org/10.11606/issn.2316-901x.voi71p95-114

HELLMANN, Risolete Maria. Crítica literária feminista: o legado de Zahidé Muzart. In: SEMINÁRIO INTERNACIONAL FAZENDO GÊNERO, 11; WOMEN'S WORLDS CONGRESS, 13, 2017, Florianópolis. Anais Eletrônicos [...]., Florianópolis: UFSC, 2017. Disponivel em: http://www.en.wwc2017.eventos.dype.com.br/ resources/anais/1499448124_ ARQUIVO_RISOLETEMARIAHELLMANN.pdf. Acesso em: 28 out. 2019.

MAGALHÃES, Flávia Denise Pires de. Feira de publicações independentes: uma análise da emergência desses encontros em Belo Horizonte (2010-2017) e dos eventos Faisca - Mercado Gráfico e Textura (2017-2018). 2018. 162 f. Dissertação (Mestrado em Estudos de Linguagens) - Centro Federal de Educação Tecnológica de Minas Gerais, Belo Horizonte, 2018. https://doi.org/10.21041/conpat2019/v3rec313

MALUMIÁN, Víctor; WINNE, Hernán López. Independientes ¿de qué? Hablan los editores de América Latina. México: Fondo de Cultura Económica, 2013. (Libros sobre Libros).

MOREIRA, Jailma dos Santos Pedreira. A produção de autoria feminina através da editora Mulheres: entrevista com Zahidé Muzart. Pontos de Interrogação, [S. l.], v. 2, n. 1, p. 315-320, jan./jun. 2012. https://doi. org/10.30620/p.i..v2i1.1546 
MUNIZ JR., José de Souza. O grito dos pequenos. Independência editorial e bibliodiversidade no Brasil e na Argentina. São Paulo: Balão Editorial, 2010.

MUNIZ JR., José de Souza. Girafas e bonsais: editores "independentes" na Argentina e no Brasil (1991-2015). 2016. 335 f. Tese (Doutorado em Sociologia) - Universidade de São Paulo, São Paulo, 2016. https://doi. org/10.11606/t.8.2016.tde-28112016-103559

MUZART, Zahidé Lupinacci. Uma espiada na imprensa das mulheres no século XIX. Estudos Feministas, Florianópolis, v. 11, n. 1, p. 225-233, jan./jun. 2003. https://doi.org/10.1590/s0104-026×2003000100013

MUZART, Zahidé Lupinacci. Histórias da editora Mulheres. Estudos Feministas, Florianópolis, v. 12, nesp. 264, p. 103-105, set./dez. 2004. https://doi. org/10.1590/s0104-026×2004000300011

OLIVEIRA, Alice Bicalho de. A independência é um modo de produção. Em Tese, Belo Horizonte, v. 22 n. 3, p. 78-89, set./dez. 2016. https://doi. org/10.17851/1982-0739.22.3.78-89

PASKO, Priscila. O gênero, a importância e o papel de uma Editora chamada Mulheres. Nonada: Jornalismo Travessia. [S. l.], 7 jan. 2016. Disponivel em: http://WwW.nonada.com.br/2016/01/o-genero-a-importancia-e-o-papel-de-uma-editora-chamada-mulheres/. Acesso em: 20 jun. 2019. https://doi. org/10.22533/at.ed.6821905062

RAMOS, Tania Regina de Oliveira. Zahidé Lupinacci Muzart. Estudos Feministas, Florianópolis, v.24, n.1, p. 181-182, jan./abr., 2016. https://doi.org/10.1590/ 1805-9584-2016v24n1p181

RIBEIRO, Ana Elisa. Boitempo Editorial e Ivana Jinkings: um quarto de século de uma editora de esquerda no Brasil. Pontos de Interrogação (Revista de Crítica Cultural), Alagoinhas, v. 9, n. 1, p. 201226, jan./jun. 2019. Disponivel em: https://www revistas.uneb.br/index.php/ pontosdeint/article/ view/7017/4627. Acesso em: 27 set. 2019. https://doi. org/10.30620/p.i..vgi1.7017

SCHMIDT, Simone Pereira; RAMOS, Tânia Regina Oliveira. Escritoras brasileiras do século XIX: antologia. Graphos: Revista da Pós-Graduação em Letras UFPB, João Pessoa, v. 7. n. 2/1, p. 219-222, 2005.

SZPILBARG, Daniela. Armas cargadas de futuro: hacia una historia feminista de la edición en Argentina. Revista Malisia, [La Plata], n. 4, p. 15-23, mayo 2018. Disponivel em: https://issuu.com/malisialibros/docs/ malisia_la_revista__4_issu. Acesso em: 22 maio 2019.

THOMPSON, John B. Mercadores de cultura. Trad. Alzira Allegro. São Paulo: Editora Unesp, 2013.

WOITOWICZ, Karina Janz. Marcos históricos da inserção das mulheres na imprensa: A conquista da escrita feminina. Jornal Alcar, Porto Alegre, n. 4, p. 1-7, out. 2012. Disponivel em: http://www.ufrgs.br/alcar/jornal-alcar-no-4-outubro-de-2012/Marcos\%20 historicos\%20da\%20insercao\%20das\%20mulheres\%20na\% 20imprensa.pdf. Acesso em: 4 maio 2019.

\section{Endereço para correspondência}

Ana Elisa Ribeiro

Av. Amazonas, 5.253

Nova Suiça 30421-169

Belo Horizonte, MG, Brasil

Sérgio Karam

Av. Paulo Gama, 110

Bairro Farroupilha 90040-060

Porto Alegre, RS, Brasil

\section{Ana Elisa Ribeiro}

Doutora em Estudos Linguísticos pela Universidade Federal de Minas Gerais, com estágio pós-doutoral no Programa de Pós-Graduação em Estudos Literários da UFMG, com pesquisa no Acervo de Escritores Mineiros. Docente da linha de pesquisa Edição, Linguagem e Tecnologia do Programa de Pós-Graduação em Estudos de Linguagens e do Bacharelado em Letras (Tecnologias da Edição) do Centro Federal de Educação Tecnológica de Minas Gerais, com projeto de pesquisa "Mulheres na Edição" (Fapemig). Autora de Livro - edição e tecnologias no século XXI (Moinhos/Contafios, 2018).

\section{Sérgio Karam}

Doutorando em Letras na Universidade Federal do Rio Grande do Sul. Tradutor. 